\title{
Fault-plane solutions from moment-tensor inversion and preliminary Coulomb stress analysis for the Emilia Plain
}

\author{
Angela Saraò ${ }^{1, \star}$, Laura Peruzza $^{1}$ \\ ${ }^{1}$ Istituto Nazionale di Oceanografia e di Geofisica Sperimentale (OGS), Sgonico (Trieste), Italy
}

\author{
Article history \\ Received July 24, 2012; accepted September 5, 2012. \\ Subject classification: \\ Emilia 2012 earthquakes, Moment tensors, Focal mechanisms, Coulomb static stress.
}

\section{Introduction}

In July 2011, at the borders of the Veneto, Lombardia and Emilia-Romagna regions, the strongest seismic sequence recorded in this area since the development of modern digital seismometric networks in Italy (in the late 1980s) occurred. The main event on July 17, $2011\left(\mathrm{M}_{\mathrm{W}}\right.$ 4.7, Figure $1 \mathrm{~A}$, white star; Table 1) was widely felt over the whole of the Po Plain, with maximum effects in the Mantova and Modena Plain $(\mathrm{V}$ Mercalli-Cancani-Sieberg [MCS], based on web questionnaires of the Istituto Nazionale di Geofisica e Vulcanologia (INGV; National Institute of Geophysics and Volcanology), www. haisentitoilterremoto.it). Other widely felt events occurred on September 13, $2011\left(\mathrm{M}_{\mathrm{L}}\right.$ 3.7), in the Veneto Piedmont area, and on October 29, $2011\left(\mathrm{M}_{\mathrm{L}} 4.4\right)$, at the northwest border of Verona Province (Avio), about $70 \mathrm{~km}$ from the July sequence. In January 2012, other earthquakes occurred in the Verona foothills and in the Parma area (Figure 1A, green and blue stars). In May 2012, a heavily damaging earthquake sequence started in the Emilia-Romagna Region (Figure 1A), where five earthquakes with $\mathrm{M}_{\mathrm{L}}>5$ occurred in less than two weeks (Table 1, Nos. 16, 21, 33, 37, 44; Figure 1A), with casualties on May, 20 and 29, 2012. The seismic activity progressively migrated westwards, and then decreased (Figure 1B, C).

We were particularly interested in the Emilia 2011 seismic sequence, as it alerted the population of the southern Veneto Region, and Istituto Nazionale di Oceanografia e di Geofisica Sperimentale (OGS, National Institute of Oceanography and Experimental Geophysics), provides seismic monitoring and alarm services to the local Civil Defence Agency. We wished to understand if the sudden increase in local seismicity should be considered a common fluctuation in the activity rates or if it could warn of the preparation of a major event, as one of the strongest events occurred in northern Italy in the XII century. Indeed, on a January 3, 1117, an earthquake with $\mathrm{M}_{\mathrm{W}} 6.7$ struck the Po Plain [Rovida et al. 2011, CPT11 hereinafter]. Recent historical studies reinterpreted the damage of the 1117 earthquake as from multiple small events over a wide area of the plain [Guidoboni et al. 2005, 2007]. Also, paleoseismological analyses have suggested controversial causative sources, with the activation of south Alpine structures in the Thiene-Bassano area, north of Vicenza [Galadini et al. 2005], or of a blind thrust in the northern Apennines, east of Parma [Galli 2005]. Conversely, the historical seismicity of the Emilia Region has been well documented since the XVI century: over the last 200 years, earthquakes have not exceeded the first damage threshold (VI MCS). The most recent events occurred on February 20, 1956, northeast of Ferrara [De Panfilis 1959], and on December 6, 1986, and May 8, 1987 (both $\mathrm{M}_{\mathrm{W}}$ ca. 4.6 in CPTI11); for these last events, the macroseismic effects and the magnitudes reported were similar to the July 17, 2011, event. Two other perceptible events $\left(\mathrm{M}_{\mathrm{L}}>3.5\right)$ are reported in the Italian instrumental catalogs [Castello et al. 2006], on November 29, 1991, and December 1, 2001. These are both missed in CPTI11, where the minimum magnitude threshold is higher than $\mathrm{M}_{\mathrm{W}}$ ca. 4.0. For the causative faults, the frontal overthrusts of the northern Apennines, which are buried under thick alluvial deposits, have been extensively investigated by borehole break-out data and seismic stratigraphy [Montone and Mariucci 1999, Fantoni and Franciosi 2010, and references therein], and recently, a geomorphological study on river diversions suggested seismogenic sources in the area [Burrato et al. 2009, DISS Working Group 2010] (see Figure 1A).

Nowadays, the seismicity of the Emilian sector of the Po Plain is detected by the INGV network [i.e., Amato and Mele 2008], and partially by the OGS seismic network [Priolo et al. 2005, Bragato et al. 2011a]. We followed the evolution of the 2012 phenomena through the OGS permanent network (Figure 1C), which was increased by eight temporary stations that were installed near to Ferrara from May 21, 2012 [Priolo et al. 2012, this volume]. The data recorded by our network were used for real-time locations and computation of moment tensors that were published on the website of the OGS Centro Ricerche Sismologiche (Seis- 

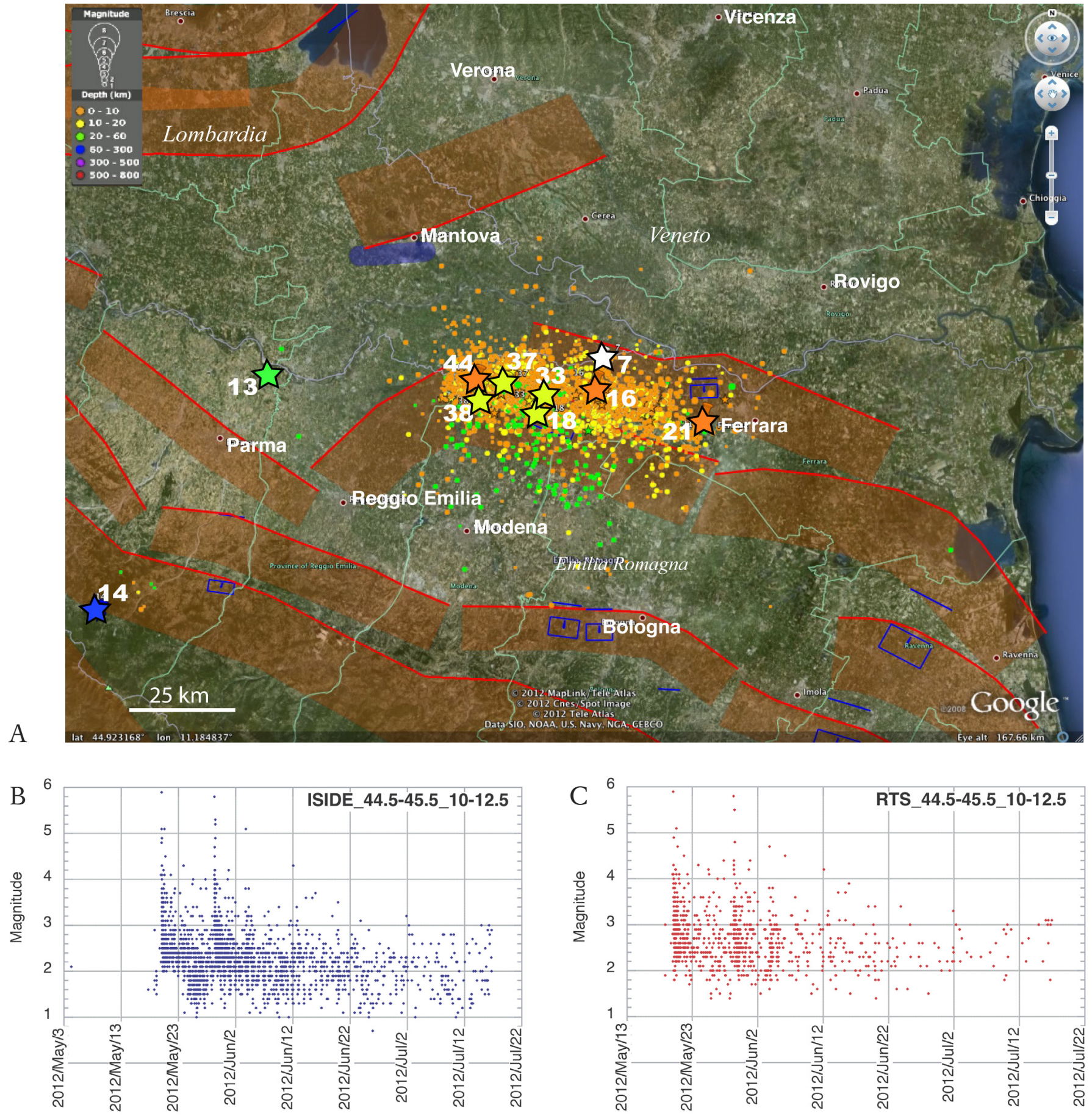

Figure 1. A. Instrumental seismicity (dots and stars) for the Po Plain, from May 1, 2012, to July 16, 2012, located inside a rectangular area of latitude 44.5 $45.5^{\circ} \mathrm{N}$, longitude $10.0-12.5^{\circ} \mathrm{E}$. Locations are from ISIDe. Stars, $\mathrm{M}_{\mathrm{W}}>4.6$ events, numbered as in Table 1, modelled as source faults in the Coulomb analysis. Orange shaded area, DISS 3.1.1 composite sources; blue rectangles, individual sources; bluish areas, debated sources. B. Magnitude versus time for the Emilia sequence, by INGV (ISIDe). C. As for (B), as reported by the OGS (RTS) databases. The ISIDe data are manually revised locations (2,277 events, 656 with $\mathrm{M} \geq 2.5$; data); the RTS data are mostly automatic solutions (946 events, 578 with $\mathrm{M} \geq 2.5$;). All of the locations are preliminary, as on July 17,2012 .

mological Research Center; http: / / rts.crs.inogs.it).

In this study, we revise the moment tensors of the seismicity that occurred from June 4, 2011, to June 15, 2012, using the waveforms collected by the OGS, and we report only the good quality fault-plane solutions of 49 events $\left(\mathrm{M}_{\mathrm{L}}\right.$ >3.6). Our focal mechanisms are then used for preliminary estimates of the Coulomb elastic stress changes, to detect potential intermediate-distance fault interactions, and to study the main features of this complex structural system.

\section{Focal mechanisms by moment-tensor analysis}

The algorithm used to compute the moment tensors is the Time-Domain Moment Tensor Inverse Code [Dreger 2002, and references therein], which was implemented at the OGS within a project supported by the Italian Civil Defence Agency (2007-2009 INGV-DPC-S3 project). The algorithm has been working routinely since 2009 , to compute moment tensors in real-time [Saraò et al. 2007, Bragato et al. 2011a], and the results are published on-line on the OGS Centro 


\begin{tabular}{|c|c|c|c|c|c|c|c|c|c|c|c|c|c|c|c|}
\hline $\mathrm{N}$ & OGSID & $\begin{array}{c}\text { Date } \\
(\text { yyyy } / \mathrm{mm} / \mathrm{dd})\end{array}$ & $\begin{array}{l}\text { Time } \\
\text { (UTC) }\end{array}$ & $\begin{array}{l}\text { Lat } \\
\left({ }^{\circ} \mathrm{N}\right)\end{array}$ & $\begin{array}{l}\text { Long } \\
\left({ }^{\circ} \mathrm{E}\right)\end{array}$ & $\begin{array}{l}\text { Depth } \\
(\mathrm{km})\end{array}$ & $\mathrm{M}_{\mathrm{L}}$ & Region & Strike & Dip & Rake & $\mathrm{Mo}(\mathrm{Nm})$ & $\begin{array}{l}\text { Mt Depth } \\
(\mathrm{km})\end{array}$ & Mw & VR \\
\hline 1 & 46574 & $2011 / 06 / 04$ & $16: 12: 03$ & 44.010 & 12.149 & 7.0 & 3.8 & Forli & $313 ; 80$ & $56 ; 48-$ & $-54 ;-131$ & $6.20 \mathrm{E}+14$ & 4 & 3.8 & 72.0 \\
\hline 2 & 46633 & $2011 / 06 / 04$ & $18: 06: 52$ & 43.930 & 12.151 & 16.0 & 4.0 & Forli & $97 ; 284$ & $55 ; 35$ & $-94 ;-84$ & $7.30 \mathrm{E}+14$ & 4 & 3.9 & 79.0 \\
\hline 3 & 48337 & $2011 / 07 / 11$ & 15:01:06 & 43.918 & 11.861 & 7.0 & 3.6 & Forli & $305 ; 121$ & $77 ; 14$ & $-89 ;-93$ & $8.90 \mathrm{E}+14$ & 2 & 3.9 & 64.0 \\
\hline 4 & 48424 & $2011 / 07 / 12$ & $06: 53: 22$ & 43.920 & 11.861 & 8.0 & 4.0 & Forli & $306 ; 114$ & $78 ; 12$ & $-88 ;-101$ & $4.60 \mathrm{E}+15$ & 2 & 4.4 & 80.0 \\
\hline 5 & 48440 & $2011 / 07 / 12$ & $07: 15: 08$ & 43.915 & 11.848 & 7.0 & 3.9 & Forli & $310 ; 119$ & $82 ; 8$ & $-88 ;-101$ & $5.90 \mathrm{E}+15$ & 2 & 4.5 & 79.0 \\
\hline 6 & 48474 & $2011 / 07 / 12$ & $19: 20: 57$ & 43.930 & 11.859 & 7.0 & 3.6 & Forli & $303 ; 108$ & $80 ; 10$ & $-87 ;-105$ & $1.80 \mathrm{E}+15$ & 2 & 4.1 & 77.0 \\
\hline 7 & 48759 & $2011 / 07 / 17$ & $18: 30: 27$ & 44.929 & 11.239 & 17.0 & 5.0 & Rovigo & $278 ; 69$ & $53 ; 40$ & $108 ; 67$ & $1.10 \mathrm{E}+16$ & 4 & 4.7 & 81.0 \\
\hline 8 & 51774 & $2011 / 09 / 08$ & $13: 17: 28$ & 44.633 & 10.391 & 29.0 & 3.8 & Parma & $109: 214$ & $80 ; 34$ & $123 ; 18$ & $4.90 \mathrm{E}+14$ & 8 & 3.8 & 71.0 \\
\hline 9 & 52477 & $2011 / 09 / 13$ & $18: 35: 23$ & 45.897 & 12.049 & 12.0 & 3.7 & Veneto & $84 ; 241$ & $69 ; 23$ & $99 ; 68$ & $1.50 \mathrm{E}+14$ & 10 & 3.4 & 66.0 \\
\hline 10 & 54528 & $2011 / 10 / 20$ & $06: 10: 51$ & 44.526 & 9.415 & 10.0 & 4.0 & Parma & $89 ; 315$ & $53 ; 47$ & $58 ; 125$ & $1.80 \mathrm{E}+15$ & 4 & 4.1 & 71.0 \\
\hline 11 & 55104 & $2011 / 10 / 29$ & $04: 13: 34$ & 45.709 & 10.957 & 11.0 & 4.4 & Avio & $245 ; 81$ & $51 ; 40$ & $79 ; 103$ & $9.70 \mathrm{E}+14$ & 10 & 4.0 & 76.0 \\
\hline 12 & 58649 & $2012 / 01 / 24$ & $23: 54: 46$ & 45.547 & 11.002 & 11.0 & 4.2 & Verona & $199 ; 107$ & $86 ; 61$ & $29 ; 176$ & $1.20 \mathrm{E}+15$ & 10 & 4.0 & 73.0 \\
\hline 13 & 58728 & $2012 / 01 / 25$ & $08: 06: 36$ & 44.895 & 10.435 & 20.0 & 5.1 & Parma & $129: 281$ & $51 ; 43$ & $-71 ;-111$ & $1.60 \mathrm{E}+16$ & 24 & 4.8 & 84.0 \\
\hline 14 & 58922 & $2012 / 01 / 27$ & $14: 53: 13$ & 44.483 & 10.033 & 61.0 & 5.4 & Parma & $274 ; 107$ & $52 ; 38$ & $81 ; 101$ & $3.00 \mathrm{E}+16$ & 50 & 4.9 & 69.0 \\
\hline 15 & 63774 & $2012 / 05 / 19$ & $23: 13: 27$ & 44.898 & 11.258 & 6.2 & 4.1 & Emilia & $273 ; 99$ & $66 ; 24$ & $88 ; 96$ & $2.00 \mathrm{E}+15$ & 6 & 4.2 & 76.5 \\
\hline 16 & 63788 & $2012 / 05 / 20$ & $02: 03: 52$ & 44.889 & 11.228 & 6.3 & 5.9 & Emilia & $282: 97$ & $51 ; 39$ & $93 ; 86$ & $1.37 \mathrm{E}+18$ & 6 & 6.1 & 74.8 \\
\hline 17 & 63810 & $2012 / 05 / 20$ & $02: 35: 37$ & 44.876 & 11.548 & 10.0 & 4.0 & Emilia & $57 ; 278$ & $55 ; 42$ & $64: 122$ & $3.80 \mathrm{E}+15$ & 4 & 4.4 & 55.7 \\
\hline 18 & 63833 & $2012 / 05 / 20$ & 03:02:50 & 44.860 & 11.095 & 10.0 & 4.9 & Emilia & $279 ; 98$ & $64 ; 26$ & $90 ; 89$ & $3.70 \mathrm{E}+16$ & 8 & 5.0 & 83.4 \\
\hline 19 & 64082 & $2012 / 05 / 20$ & $10: 12: 22$ & 44.915 & 11.132 & 5.2 & 3.8 & Emilia & $82 ; 266$ & $48 ; 42$ & $88 ; 93$ & $8.58 \mathrm{E}+14$ & 8 & 3.9 & 50.1 \\
\hline 20 & 64163 & $2012 / 05 / 20$ & $12: 50: 24$ & 44.866 & 11.366 & 2.2 & 3.9 & Emilia & $88 ; 236$ & $52 ; 42$ & $111 ; 66$ & $8.41 \mathrm{E}+14$ & 8 & 3.9 & 60.3 \\
\hline 21 & 64179 & $2012 / 05 / 20$ & $13: 18: 02$ & 44.831 & 11.490 & 4.7 & 5.1 & Emilia & $284 ; 114$ & $64 ; 26$ & $85 ; 99$ & $5.67 \mathrm{E}+16$ & 4 & 5.1 & 78.8 \\
\hline 22 & 64276 & $2012 / 05 / 20$ & $17: 37: 14$ & 44.876 & 11.382 & 3.2 & 4.5 & Emilia & $75 ; 235$ & $47 ; 45$ & $104 ; 75$ & $4.18 \mathrm{E}+15$ & 6 & 4.4 & 59.5 \\
\hline 23 & 64389 & $2012 / 05 / 20$ & $22: 22: 45$ & 44.836 & 11.479 & 5.0 & 3.6 & Emilia & $284 ; 110$ & $51 ; 39$ & $86 ; 95$ & $4.75 \mathrm{E}+14$ & 8 & 3.8 & 65.2 \\
\hline 24 & 64594 & $2012 / 05 / 21$ & $16: 37: 31$ & 44.851 & 11.348 & 10.4 & 4.1 & Emilia & $63 ; 228$ & $59 ; 32$ & $98 ; 77$ & $1.50 \mathrm{E}+15$ & 6 & 4.1 & 75.2 \\
\hline 25 & 64781 & $2012 / 05 / 22$ & $06: 11: 15$ & 44.850 & 11.074 & 6.9 & 3.7 & Emilia & $281 ; 63$ & $57 ; 39$ & $113 ; 59$ & $3.48 \mathrm{E}+14$ & 4 & 3.7 & 70.8 \\
\hline 26 & 64833 & $2012 / 05 / 22$ & $09: 31: 14$ & 44.850 & 11.265 & 14.9 & 3.8 & Emilia & $266 ; 92$ & $62 ; 28$ & $87 ; 95$ & $7.1 \mathrm{E}+14$ & 10 & 3.9 & 71.2 \\
\hline 27 & 65009 & $2012 / 05 / 23$ & $21: 41: 18$ & 44.868 & 11.251 & 4.8 & 4.3 & Emilia & $271 ; 105$ & $57 ; 33$ & $83 ; 101$ & $1.47 \mathrm{E}+14$ & 6 & 4.1 & 77.1 \\
\hline 28 & 65178 & $2012 / 05 / 25$ & $10: 31: 23$ & 44.861 & 11.258 & 6.1 & 3.9 & Emilia & $99 ; 271$ & $57 ; 33$ & $95 ; 83$ & $8.50 \mathrm{E}+14$ & 8 & 3.9 & 71.0 \\
\hline 29 & 65213 & $2012 / 05 / 25$ & $13: 14: 05$ & 44.883 & 11.108 & 10.0 & 4.0 & Emilia & $269 ; 77$ & $45 ; 45$ & $99 ; 81$ & $7.19 \mathrm{E}+14$ & 6 & 3.9 & 81.1 \\
\hline 30 & 65318 & $2012 / 05 / 26$ & $21: 07: 32$ & 44.838 & 11.188 & 10.4 & 3.8 & Emilia & $107 ; 17$ & $86 ; 84$ & $174 ;-4$ & $3.51 \mathrm{E}+14$ & 6 & 3.7 & 72 \\
\hline 31 & 65420 & $2012 / 05 / 27$ & $18: 18: 45$ & 44.882 & 11.158 & 4.7 & 4.0 & Emilia & $314 ; 224$ & $90 ; 85$ & $175 ; 0$ & $7.96 \mathrm{E}+14$ & 4 & 3.9 & 88.6 \\
\hline 32 & 65431 & $2012 / 05 / 27$ & $20: 25: 43$ & 44.892 & 11.150 & 4.1 & 3.8 & Emilia & $244 ; 121$ & $72 ; 31$ & $64 ; 143$ & $6.63 \mathrm{E}+14$ & 6 & 3.8 & 62.6 \\
\hline 33 & 65605 & $2012 / 05 / 29$ & $07: 00: 03$ & 44.851 & 11.086 & 10.2 & 5.8 & Emilia & $274 ; 97$ & $64 ; 26$ & $89 ; 93$ & $7.66 \mathrm{E}+17$ & 6 & 5.9 & 80.2 \\
\hline 34 & 65653 & $2012 / 05 / 29$ & $08: 25: 51$ & 44.901 & 10.943 & 3.2 & 4.5 & Emilia & $279 ; 97$ & $68 ; 22$ & $91 ; 88$ & $9.41 \mathrm{E}+15$ & 6 & 4.6 & 78.3 \\
\hline 35 & 65674 & $2012 / 05 / 29$ & $08: 40: 57$ & 44.892 & 10.962 & 5.3 & 4.2 & Emilia & $285 ; 103$ & $68 ; 22$ & $91 ; 88$ & $3.67 \mathrm{E}+15$ & 6 & 4.3 & 69.5 \\
\hline 36 & 65719 & $2012 / 05 / 29$ & 09:30:21 & 44.892 & 11.053 & 1.2 & 4.2 & Emilia & $255 ; 97$ & $67 ; 25$ & $81 ; 110$ & $9.93 \mathrm{E}+14$ & 6 & 4.0 & 73.9 \\
\hline 37 & 65755 & $2012 / 05 / 29$ & $10: 55: 57$ & 44.888 & 11.008 & 6.8 & 5.3 & Emilia & $269 ; 105$ & $65 ; 26$ & $83 ; 105$ & $2.28 \mathrm{E}+17$ & 6 & 5.5 & 62.4 \\
\hline 38 & 65763 & $2012 / 05 / 29$ & $11: 00: 02$ & 44.873 & 10.950 & 11.0 & 4.9 & Emilia & $293 ; 75$ & $61 ; 34$ & $110 ; 58$ & $2.68 \mathrm{E}+16$ & 4 & 4.9 & 81.1 \\
\hline 39 & 65824 & $2012 / 05 / 29$ & $14: 39: 40$ & 44.882 & 11.068 & 20.6 & 3.9 & Emilia & $56 ; 146$ & $89 ; 85$ & $-5 ; 179$ & $4 \mathrm{E}+14$ & 20 & 3.7 & 63.9 \\
\hline 40 & 65872 & $2012 / 05 / 29$ & 18:28:01 & 44.921 & 10.947 & 2.7 & 3.9 & Emilia & $267 ; 104$ & $68 ; 23$ & $83 ; 106$ & $1.06 \mathrm{E}+15$ & 6 & 4.0 & 71.7 \\
\hline 41 & 66097 & $2012 / 05 / 30$ & $06: 00: 33$ & 44.931 & 10.937 & 5.0 & 3.8 & Emilia & $87 ; 265$ & $56 ; 34$ & $91 ; 88$ & $5,53 \mathrm{E}+14$ & 4 & 3.8 & 52.5 \\
\hline 42 & 66327 & $2012 / 05 / 31$ & $06: 55: 49$ & 44.880 & 10.867 & 5.8 & 4.0 & Emilia & $278 ; 75$ & $57 ; 36$ & $103 ; 71$ & $8.99 \mathrm{E}+14$ & 8 & 3.9 & 73.6 \\
\hline 43 & 66366 & $2012 / 05 / 31$ & 19:04:04 & 44.891 & 10.980 & 8.7 & 4.2 & Emilia & $97 ; 280$ & $49 ; 41$ & $92 ;-88$ & $7.11 \mathrm{E}+14$ & 10 & 3.9 & 74.4 \\
\hline 44 & 66637 & $2012 / 06 / 03$ & $19: 20: 43$ & 44.899 & 10.943 & 9.2 & 5.1 & Emilia & $288 ; 96$ & $67 ; 24$ & $95 ; 79$ & $1.82 \mathrm{E}+16$ & 15 & 4.8 & 76.8 \\
\hline 45 & 66799 & $2012 / 06 / 04$ & $06: 55: 49$ & 44.926 & 10.980 & 5.0 & 3.8 & Emilia & $273 ; 91$ & $58 ; 32$ & $91 ; 88$ & $9.21 \mathrm{e}+14$ & 6 & 3.9 & 63.3 \\
\hline 46 & 67001 & $2012 / 06 / 06$ & $04: 08: 33$ & 44.434 & 12.354 & 25.6 & 4.5 & Emilia & $270 ; 26$ & $71 ; 37$ & $123 ; 32$ & $1.40 \mathrm{E}+15$ & 12 & 4.1 & 77.7 \\
\hline 47 & 67183 & $2012 / 06 / 09$ & 02:04:56 & 46.209 & 12.444 & 7.1 & 4.5 & Barcis & $55 ; 222$ & $65 ; 25$ & $96 ; 78$ & $1.58 \mathrm{E}+15$ & 16 & 4.1 & 62.2 \\
\hline 48 & 67353 & $2012 / 06 / 12$ & 01:48:36 & 44.880 & 10.888 & 10.8 & 4.3 & Emilia & $276 ; 85$ & $65 ; 26$ & $95 ; 80$ & $1.77 \mathrm{E}+15$ & 8 & 4.1 & 79.5 \\
\hline 49 & 67538 & $2012 / 06 / 15$ & $22: 13: 49$ & 44.893 & 11.324 & 3.1 & 3.7 & Emilia & $118 ; 269$ & $49 ; 45$ & $110 ; 68$ & $4.29 \mathrm{E}+14$ & 6 & 3.7 & 74.4 \\
\hline
\end{tabular}

Table 1. Dataset of the focal mechanisms released for this study. Gray highlighted events are used as source faults for the Coulomb stress analysis. Locations are taken from ISIDe, except for event Nos. 7, 9, 11 and 47, which are taken from OGS bulletins. Mo, seismic moment; Mt, moment tensor; VR, variance reduction; FPS, fault plane solution. 
Ricerche Sismologiche website. The seismicity that occurred in the Emilia-Romagna region was well detected by the OGS network, also because of the Moho reflection effects recognized in the Po Plain [Bragato et al. 2011b], which amplify the recorded signals at hypocentral distances between $90 \mathrm{~km}$ and $150 \mathrm{~km}$. This effect favors the recording of good quality data by the northeastern Italy stations, also at long periods.

The data used in this study are broadband waveforms that were recorded by stations belonging to the north-eastern Italy seismic network, which is managed by OGS and is designed to monitor the seismic activity of north-eastern Italy and its surroundings. This includes 14 digital broadband stations that are equipped with Streckeisen STS- 2 and STS- 1 or Nanometrics Trillium 40 and 120 seismometers, coupled with Q330 and Q128 Quanterra data loggers. The data quality is routinely checked, to maintain a good level of signal-tonoise ratio. Data from other Institutes (e.g., INGV, Austrian ZAMG, Provincia Autonoma di Trento, Provincia Autonoma di Bolzano) are commonly exchanged in real-time with the OGS [see Bragato et al. 2011a, for futher details], and they are used to better constrain inversion results.

For the present study, we computed the moment tensors of more than 80 events with $M_{L}>3.6$ that occurred from June 4 , 2011, to June 15,2012 . Only good quality solutions that were obtained by more than four stations and with a variance reduction $>50$ were used, as reported in Table 1 . The vari- ance reduction is a quality index of the waveform fit between the observed and the synthetic seismograms, and it is equal to the sum of the squares of the difference in amplitude normalized by the observed waveforms ( $100 \%$ is the best fit).

The recorded waveforms were sampled at 100 sps and extracted in $600 \mathrm{~s}$ time windows, starting 2 min before the origin time of each event. After correction for the instrument response, the waveforms were integrated, to obtain the displacement, resampled at $1 \mathrm{sps}$, and bandpass filtered in the frequency band of $0.02 \mathrm{~Hz}$ to $0.05 \mathrm{~Hz}$, to reduce the structural model effects. All of the main parameter solutions are reported in Table 1. As an example, Figure 2 shows the moment-tensor solution and waveform fit for the mainshock of the Emilia 2012 sequence.

Sensitivity tests on the algorithm used to compute the moment tensors [i.e. Dreger and Helmberger 1993, Saraò 2007] revealed that the source mechanism can be obtained confidently from sparse stations despite possible errors in source location, and that full azimuthal coverage is not required when three-component station data are used and the structural model is adequately known. We used the one-dimensional velocity model of Bressan [2005], and for the Emilia 2012 sequence, the velocity model recently proposed for the Po and the Venetian Plains by Vuan et al. [2011]. This last model was reconstructed from oil exploration data, deep seismic soundings, and seismic reflection measurements, and it was validated
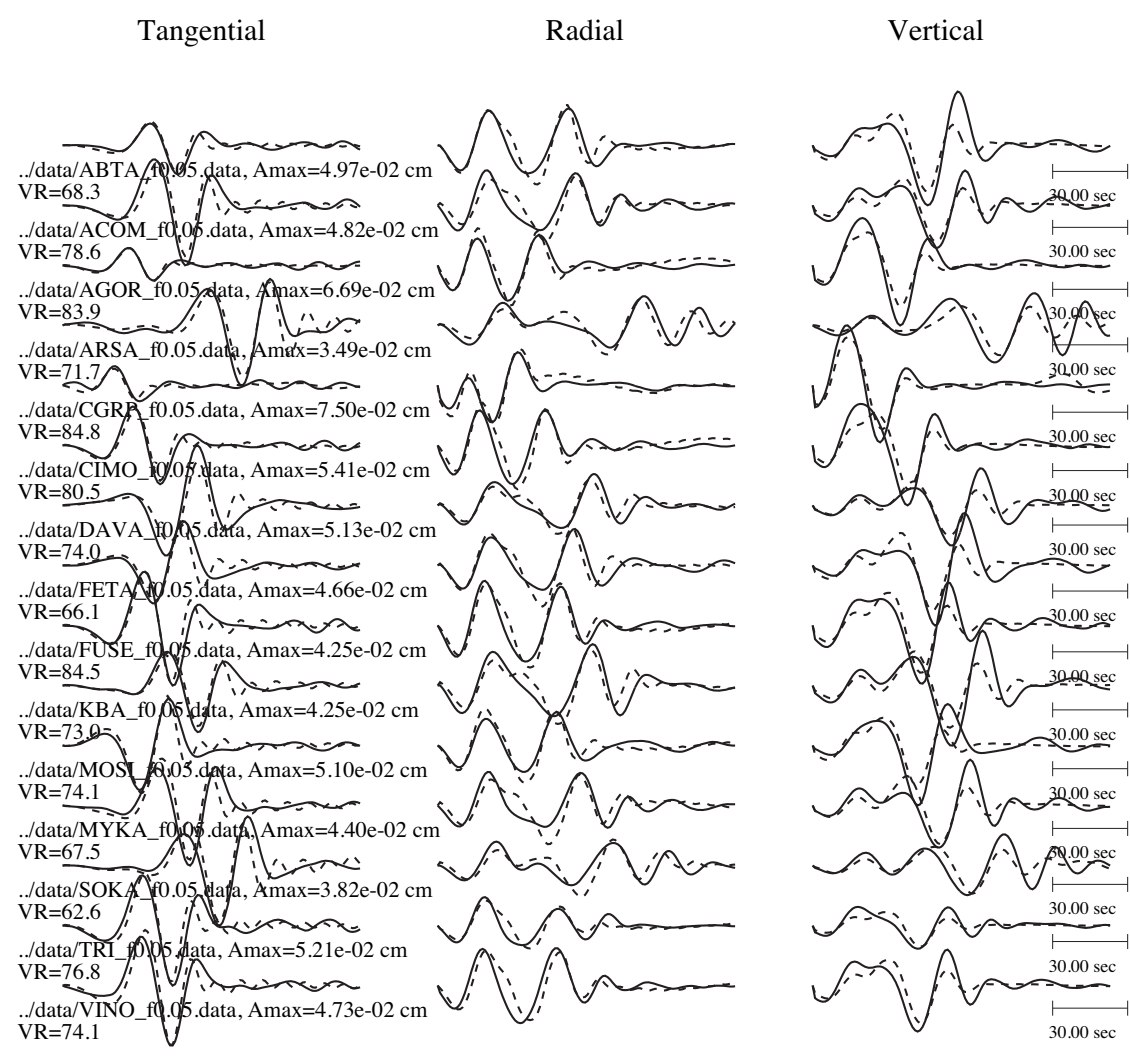

CRS EVENT ID=63788-64998

2012/05/20 02:03:52

Depth $=6 \mathrm{~km}$

Strike $=282 ; 97$

Rake $=93 ; 86$

Dip $=51 ; 39$

Mo $=1.37 \mathrm{e}+25$ dyn $\mathrm{cm}$

$\mathrm{Mw}=6.1$

Percent $\mathrm{DC}=98$

Percent CLVD=2

Percent ISO=0 (fixed)

Variance $=4.36 \mathrm{e}-05$

Var. Red $=7.48 \mathrm{e}+01$

RES/Pdc. $=4.44 \mathrm{e}-07$

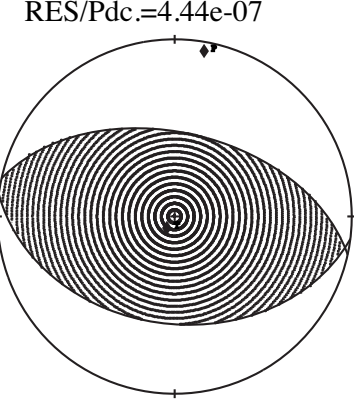

Figure 2. Waveform fit and moment-tensor solution for the May 20, 2012, event at 02:03:52 ( $\mathrm{M}_{\mathrm{W}}$ 6.1). Details about the stations can be found on the OGSCRS website (http://rts.crs.inogs.it/). 
by comparing recorded waveforms from medium-sized earthquakes in the period range from $1 \mathrm{~s}$ to $40 \mathrm{~s}$.

Since the OGS stations coverage was not optimal to robustly constrain the depth locations of the events by moment-tensor computation, for the Coulomb stress analysis we preferred to use the depth locations on line published in the Italian Seismological Instrumental and Parametric Database (ISIDe hereinafter) [ISIDe Working Group 2010] as extracted on July 17, 2012, for all but event Nos. 7, 9, 11 and 47 (Table 1), which occurred within the OGS network coverage area. Concerning event No. 7 , we used the deep location given by the OGS bulletin $(16.8 \mathrm{~km}$, versus the $2.4 \mathrm{~km}$ in the INGV bulletin), chosen because no damage was reported for this event, and the decay of macroseismic intensity with distance was not as sharp as expected from a surficial earthquake (see http: / / www.haisentitoilterremoto.it/repository/ $2218487900 /$ index.html, depth assigned at $8.1 \mathrm{~km}$ ). However, the nearest stations available at the time of the earthquake were at about $20 \mathrm{~km}$ (GAZZ for OGS) and $30 \mathrm{~km}$ (RAVA for INGV) distance, and therefore it was difficult to constrain the depth correctly.

\section{Coulomb stress change analysis}

We investigated elastic stress changes using the set of focal mechanisms reported in Table 1. These were spread over a large area, and cover about one year of monitoring, as the initial intent of our study was to investigate potential intermediate-distance fault interactions; e.g., similar to what was proposed by Nostro et al. [2005], and more recently by Okada et al. [2011]. To achieve our goal, we used the Coulomb 3.2 code [Lin and Stein 2004, Toda et al. 2005]. We selected 10 events (Table 1, highlighted in gray; Figure 1, stars) with $\mathrm{M}_{\mathrm{W}}>4.6$ as source faults, assuming that these sources impart stress to the surrounding crust and faults. This assumption appears relatively strong, as it implies that all of the other events have a negligible role in earthquake interactions, whereas some studies have demonstrated the importance of small events for stress redistribution [e.g., Helmstetter et al. 2005, Marsan 2005]. However, interactions act on volumes proportional to the rupture dimension: the literature [e.g., Hardebeck et al. 1998] and the tests we carried out show that the static stress changes vanish at 1-3times the rupture length; in our case, for magnitude smaller than 4.5 , the interaction distances are of the same size as the earthquake location uncertainties (about $1 \mathrm{~km}$ for the horizontal errors, and higher values in depth assessments). Moreover, we chose a magnitude cut-off to guarantee a complete dataset of source faults. Indeed, we rejected some low-quality moment-tensor solutions, and our focal-mechanism database (Table 1) is not complete for $\mathrm{M}_{\mathrm{L}}<3.8$.

Fault size and slip were computed by the Wells and Coppersmith [1994] relationships embedded in the code (reverse faults for all but event No. 13). The uniform slip distribution is considered an acceptable approximation, given the magnitudes of the events. The cross-sections on the ca. 2,700 preliminary hypocenters of the Emilia 2012 sequence (as located on July $17,2012)$ suggested a global pattern of an S-dipping volume, although they did not enhance peculiar alignments on fault traces, or sometimes showed fake alignments due to locations forced to a fixed depth. Therefore we started our analysis by imposing on all the source faults the E-W striking, S-dipping solution, in agreement with the geological interpretation of the sources (composite and individual) given in DISS 3.1.1 (Figure 3A), and with the results of the preliminary analysis of the Synthetic Aperture Radar (SAR) data [Atzori et al. 2012]. Then, with a trial and error procedure, we modified some source orientations using the antithetic fault plane as well. We ran the cumulative stress change of all the previous events to the subsequent one iteratively, and mapped the redistribution after the occurrence of all of the 10 considered sources, at given depth and on some cross-sections, as shown in Figure 3. Different friction values were tested, and a simple quantitative estimate of the goodness of the modeling is given by the Coulomb index [Hardebeck et al. 1998], which accounts for the percentage of events that occur on positive stress changes. We present here only the more significant tests carried out.

The cumulative Coulomb stress-change map at $7 \mathrm{~km}$ in depth is plotted in Figure 3A, and was obtained considering the S-dipping planes of the focal mechanisms of the 10 sources. Figure 3B was obtained by modeling eight S-dipping planes and the two main events of May 20 and 29, 2012, by antithetic faults (N-dipping, high angle). They look quite similar, although some differences appear in the E-W oriented crosssections spaced 5-km apart (Figure 3C, D). The correlation of the hypocenters with the areas of enhanced Coulomb stress obtained by modeling the main events by antithetic faults (Figure 3B, D, reddish zones) show that more than $80 \%$ of the selected earthquakes were in a positive Coulomb shadow; i.e., a higher percentage than that obtained by the model of Figure 3A, C. Quantitative computation of the normal and total Coulomb stress on the focal mechanism solutions enabled us to select the preferred plane, and to statistically select the best model; these results will be compared with high-quality relocated events as soon as they are available.

Sources 7, 13 and 14 were active before the 2012 sequence. The sources in the Parma district $(13,14)$ are too far and too deep to interact by static stress changes with the system of faults activated during the Emilia 2012 sequence. The deep events that occurred before the main shocks (e.g., July $17,2011)$ were located in stress shadows of the global stress representations (Figure 3C, D, bluish areas). To constrain the results, additional time-dependent representations and a more complex system interactions that take into account, for instance, the fluid components too [i.e., Nostro et al. 2005], remain necessary. A set of well-constrained hypocenter locations is necessary to confirm these results. 

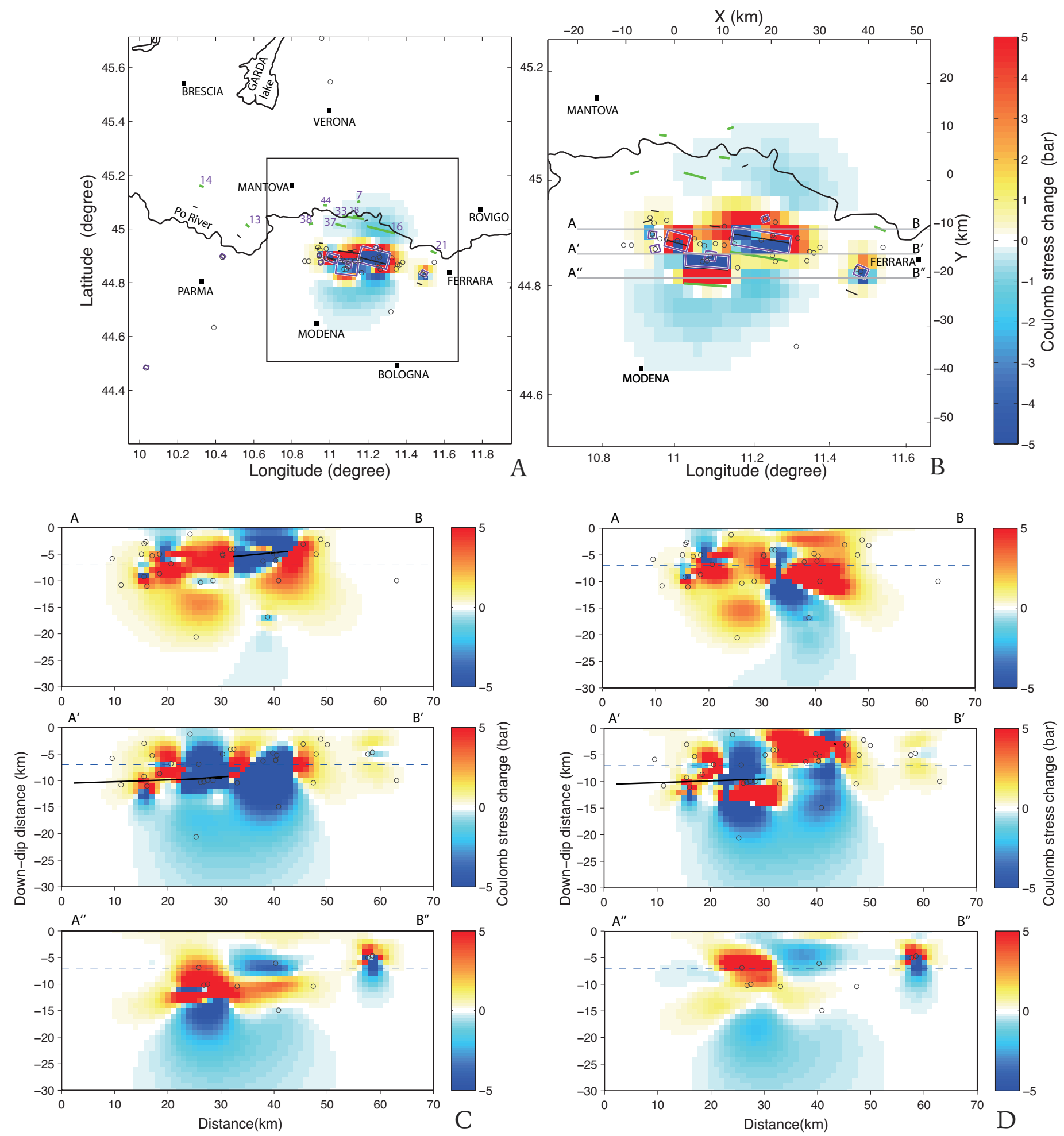

Figure 3. Coulomb stress change analyses in the Po Plain hit by the Emilia 2012 sequence. A. Coulomb stress change map at $7 \mathrm{~km}$ depth, with the fault model given by 10 S-dipping sources. Pink rectangles, ruptures; numbers of the source, written beside the hypothetical intersection of the planes at the surface (green traits); small black circles, focal mechanism dataset. B. As for A), but sources No. 16 and 33 are modeled by N-dipping fault planes. C. Coulomb stress change profiles for the model of Figure 3A, with the position of the sections given in Figure 3B. D. As for (C), using the fault model of Figure 3B. Black sub-horizontal traits in some profiles, ruptures intersected by the profile (apparent inclination).

\section{Conclusions}

High-quality moment-tensor solutions of 49 events $\left(\mathrm{M}_{\mathrm{L}}>3.6\right)$ are provided within this study, and they were used to perform a first Coulomb stress analysis. Even if this is still preliminary, for the two most energetic events that occurred on May 20 and 29, 2012, our modeling of the Emilia sequence suggests the possible activation of the auxiliary plane of focal mechanisms with respect to the S-dipping plane traditionally given by geological interpretation of seismogenic sources. The Emilia 2012 sequence was formed by several events of 
medium-to-small magnitude. As in a homogeneous elastic crust the stress vanishes at about the same distance as the rupture dimension, the analysis should be performed on a very local scale; lateral variations are notable even in the order of a few kilometers. Therefore, the uncertainties related to the hypocenter locations have to be taken into account correctly. A careful statistical evaluation of these early results is still ongoing, although a set of well-constrained hypocenter locations is mandatory to confirm our hypotheses, with some testing by heterogeneous slip distribution. Additional representations of the time evolution of the sequence will shine a light on the complex phenomena, like, for instance, the possible role of fluids. Our initial intent to verify the potential medium-distance interactions between the 2011 events that were on both sides of the Po Plain did not obtain an answer within this study. Of course, multidisciplinary investigations based on geophysical measurements are needed to study the role of the Emilia sequence in promoting, or inhibiting, a major earthquake by static stress changes.

Acknowledgements. We are grateful to A. Akinci and F. Catalli for their careful review and constructive comments that helped us to improve the original manuscript. Thanks to R. Stein for his words of encouragement, and to A. Vuan for useful suggestions. The colleagues of OGS-CRS, INGV and the ISIDe Working Group are acknowledged for the maintenance of the seismic networks and the compilation of bulletins and realtime databases.

\section{References}

Amato, A., and F. Mele (2008). Performance of the INGV National Seismic Network from 1997 to 2007, Annals of Geophysics, 51 (2/3), 417-431; doi:10.4401/ag-4454.

Atzori, S., J. Merryman Boncori, G. Pezzo, C. Tolomei and S. Salvi (2012). Secondo report analisi dati SAR e modellazione della sorgente del terremoto dell'Emilia, Open Report File, 5 pp.; www.sigris.it

Bragato, P.L., P. Di Bartolomeo, D. Pesaresi, M. Plasencia Linares and A. Saraò (2011a). Acquiring, archiving, analyzing and exchanging seismic data in real time at the Seismological Research Center of the OGS in Italy, Annals of Geophysics, 54 (1), 67-75; doi:10.4401/ag-4958.

Bragato, P.L., M. Sugan, P. Augliera, M. Massa, A. Vuan and A. Saraò (2011b). Moho reflection effects in the Po Plain (northern Italy) observed from instrumental and intensity data, B. Seismol. Soc. Am., 101, 2142-2152.

Bressan, G. (2005). Modelli di velocità 1D dell'Italia Nord Orientale, Internal Report OGS, CRS / 5/20/2005, Udine, December 2005, 18 pp.

Burrato, P., F. Ciucci and G. Valensise (2009). An inventory of river anomalies in the Po Plain, northern Italy: evidence for active blind thrust faulting, Annals of Geophysics, 46 (5); doi:10.4401/ag-3459.

Castello, B., G. Selvaggi, C. Chiarabba and A. Amato (2006). CSI Catalogo della sismicità italiana 1981-2002, versione
1.1, INGV-CNT, Roma; http:/ / www.ingv.it/CSI /

De Panfilis, M. (1959). Attività sismica in italia dal 1953 al 1957, Annali di Geofisica, 12 (1), 23-148; doi:10.4401/ag5513; available at http:/ / www.annalsofgeophysics.eu/ index.php/annals/issue/archive

DISS Working Group (2010). Database of Individual Seismogenic Sources (DISS), Version 3.1.1: A compilation of potential sources for earthquakes larger than M 5.5 in Italy and surrounding areas; http: / / diss.rm.ingv.it/ diss

Dreger, D.S. (2002). TDMT_INV: time-domain seismic moment tensor inversio, In: W.H.K. Lee, H. Kanamori, P.C. Jennings and C. Kisslinger (eds.), International Handbook of Earthquake and Engineering Seismology, Part B, Academic Press, Amsterdam, p. 1627 and files on attached CD-ROM.

Dreger, D.S., and D.V. Helmberger (1993). Determination of source parameters at regional distances with three component sparse network data, J. Geophysics. Res., 98, 8107-8125.

Fantoni, R., and R. Franciosi (2010). Tectono-sedimentary setting of the Po Plain and Adriatic foreland, Rendiconti Lincei, 21, 197-209; doi:10.1007/s12210-010-0102-4.

Galadini, F., M.E. Poli and A. Zanferrari (2005). Seismogenic sources potentially responsible for earthquakes with $M \geq 6$ in the eastern Southern Alps (Thiene-Udine sector, NE Italy), Geophys. J. Int., 161,739-762; doi:10.1111/j.1365246X.2005.02571.X.

Galli, P. (2005). I terremoti del gennaio 1117. Ipotesi di un epicentro nel Cremonese, Ital. J. Quaternary Sci., 18, 87-100.

Guidoboni, E., A. Comastri and E. Boschi (2005). The "exceptional" earthquake of 3 January 1117 in the Verona area (northern Italy): A critical time review and detection of two lost earthquakes (lower Germany and Tuscany), J. Geophys. Res., 110, B12309; doi:10.1029/2005JB 003683.

Guidoboni, E., G. Ferrari, D. Mariotti, A. Comastri, G. Tarabusi and G. Valensise (2007). CFTI4Med, Catalogue of Strong Earthquakes in Italy from 461 B.C. to 2000 and in the Mediterranean area, from 760 B.C. to 1500 , An Advanced Laboratory of Historical Seismology; http:/ / storing.ingv.it/cfti4med/

Hardebeck, J.L., J.J. Nazareth and E. Hauksson (1998). The static stress change triggering model: Constraints from two southern California aftershock sequences, J. Geophys. Res., 103 (B10); doi:10.1029/98JB00573.

Helmstetter, A., Y.Y. Kagan and D.D. Jackson (2005). Importance of small earthquakes for stress transfers and earthquake triggering, J. Geophys. Res., 110, B05S08; doi: $10.1029 / 2004 J B 003286$.

ISIDe Working Group - INGV (2010). Italian Seismological Instrumental and parametric database; http://iside.rm. ingvit 
Lin, J., and R.S. Stein (2004). Stress triggering in thrust and subduction earthquakes, and stress interaction between the southern San Andreas and nearby thrust and strikeslip faults, J. Geophys. Res., 109, B02303; doi:10.1029/ 2003JB002607.

Marsan, D. (2005). The role of small earthquakes in redistributing crustal elastic stress, Geophys. J. Int., 163, 141151; doi:10.1111/j.1365-246X.2005.02700.x.

Montone, P., and M.T. Mariucci (1999). Active stress along the NE external margin of the Apennines: The Ferrara arc, northern Italy, J. Geodyn., 28, 251-265.

Nostro, C., L. Chiaraluce, M. Cocco, D. Baumont and O. Scotti (2005). Coulomb stress changes caused by repeated normal faulting earthquakes during the 1997 UmbriaMarche (central Italy) seismic sequence, J. Geophys. Res., 110, B05S20; doi:10.1029/2004JB003386.

Okada, T., K. Yoshida, S. Ueki, J. Nakajima, N. Uchida, T. Matsuzawa, N. Umino, A. Hasegawa and Group for the aftershock observations of the 2011 off the Pacific coast of Tohoku Earthquake (2011). Shallow inland earthquakes in NE Japan possibly triggered by the 2011 off the Pacific coast of Tohoku Earthquake, Earth Planets Space, 63, 749-754.

Priolo, E., and 24 coauthors (2005). Seismic monitoring in Northeastern Italy: a ten-year experience, Seismol. Res. Lett., 76, 446-454.

Priolo, E., M. Romanelli, C. Barnaba, M. Mucciarelli, G. Laurenzano, L. Dall'Olio, N. Abu-Zeid, R. Caputo, G. Santarato, L. Vignola, C. Lizza and P. Di Bartolomeo (2012). The Ferrara thrust earthquakes of May-June 2012: preliminary site response analysis at the sites of the OGS temporary network, Annals of Geophysics, 55 (4); doi: $10.4401 /$ ag-6172.

Rovida, A., R. Camassi, P. Gasperini and M. Stucchi, eds. (2011). CPTI11, the 2011 version of the Parametric Catalogue of Italian Earthquakes. Milano, Bologna; http:/ / emidius.mi.ingv.it/CPTI

Saraò, A. (2007). Seismic moment tensor determination at CRS: feasibility study, Internal Report OGS-CRS, 43 pp.

Toda, S., R.S. Stein, K. Richards-Dinger and S. Bozkurt (2005). Forecasting the evolution of seismicity in southern California: Animations built on earthquake stress transfer, J. Geophys. Res., 110, B05S16; doi:10.1029/2004 JB003415.

Vuan, A., P. Klin, G. Laurenzano and E. Priolo (2011). FarSource Long-Period Displacement Response Spectra in the Po and Venetian Plains (Italy) from 3D Wavefield Simulations, B. Seismol. Soc. Am., 101, 1055-1072; doi:10.1785/ 0120090371.

Wells, D.L., and K.J. Coppersmith (1994). Analysis of Empirical Relationships among Magnitude, Rupture Length, Rupture Area, and Surface Displacement, B. Seismol. Soc. Am., 84, 974-1002.

\footnotetext{
${ }^{\star}$ Corresponding author: Angela Saraò, Istituto Nazionale di Oceanografia e di Geofisica Sperimentale (OGS), Sgonico (Trieste), Italy; email: asarao@inogs.it.

(C) 2012 by the Istituto Nazionale di Geofisica e Vulcanologia. All rights reserved.
} 